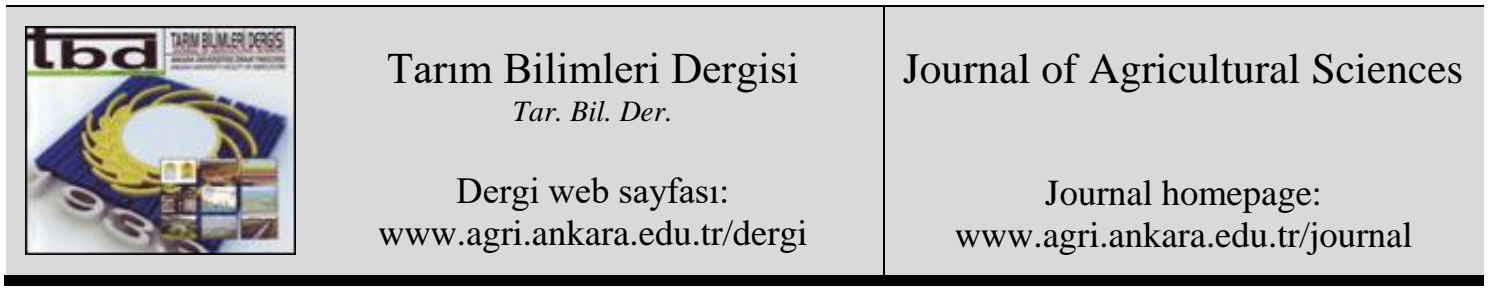

\title{
Meta-analysis of the Effects of Salinity Stress on Cotton (Gossypium spp.) Growth and Yield in Iran
}

\author{
Azadeh RAZAJI ${ }^{a}$, Farzad PAKNEJAD ${ }^{\text {b }}$, Maryam MOAREFI ${ }^{c}$, Abdolmajid MAHDAVI DAMGHANI $^{d}$, \\ Mohammad NABI ILKAEE ${ }^{\mathrm{e}}$

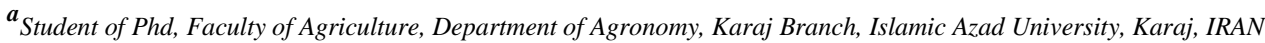

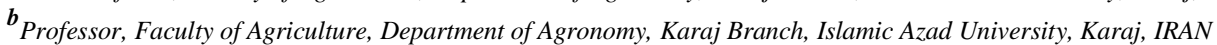

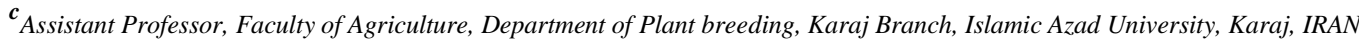

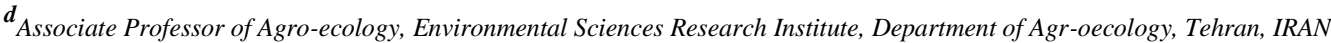

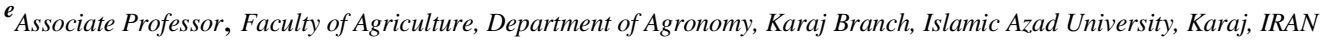

\section{ARTICLE INFO}

Research Article

Corresponding Author: Farzad PAKNEJAD, E-mail: farzadpaknejad@yahoo.com, Tel: +98 (0263) 4418143

Received: 28 November 2018, Received in Revised Form: 05 January 2019, Accepted: 31 January 2019

\section{AUTHORS ORCID ID}

(Azadeh RAZAJI: 0000-0001-9128-0631), (Farzad PAKNEJAD: 0000-0003-0951-2072), (Maryam MOAREFI: 0000-00032726-3508), (Abdolmajid MAHDAVI DAMGHANI: 0000-0003-4280-7200), (Mohammad NABI ILKAEE: 0000-00021374-9462)

\begin{abstract}
Research on the impact of inputs has a long history in the country; however, because of the dispersion and diversity in the results of various experiments, it is difficult to achieve a general conclusion. In this study, a meta-analysis approach has been used to overcome this problem in order to achieve a single result by integrating and re-analyzing the findings of independent experiments. For this purpose, scientific articles published by researchers of the country regarding the effect of salinity stress on cotton yield were investigated. Articles were selected so that, in their meta-analysis of data required to perform there. The data necessary for the implementation of the meta-analysis is present in them. The results of this study showed that from 1996 to $2017 ; 15$ papers and thesis were published on the effects of salinity stress on yield, early maturing and number of bolls in upland cotton (Gossypiumhirsutum L.). With increasing salinity stress,
\end{abstract}

yield and number of bolls decreased. The standardized values for salinity stress effect on cotton yield were significant in all five treatments (control via salinity, control via $2-3 \mathrm{dS} \mathrm{m}^{-1}$, control via 4-5 dS m${ }^{-1}$, control via 6-7 $\mathrm{dS} \mathrm{m}^{-1}$, control via 8$\left.9 \mathrm{dS} \mathrm{m}^{-1}\right)$ compared to control $(\mathrm{P}<0.001)$. The standardized values of the effect of salt stress on cotton aging were significant in all five treatments compared to control. The standardized values of the effect of salt stress on cotton aging were significant in all five treatments compared to control. Results showed increasing salinity stress can cause early maturing in cotton. The standardized values for the effect of salinity stress on number of bolls per cotton plant, in the comparison of the total treatments of salinity stress, 2-3 dS $\mathrm{m}^{-1}, 6-7 \mathrm{dS} \mathrm{m}^{-1}$ and 8-9 $\mathrm{dS} \mathrm{m}^{-1}$ were significant compared to control $(\mathrm{P}<0.001)$. In general, the results of this study showed that salinity stress can reduce yield of cotton by reducing the number of bolls and also can cause early maturing on cotton.

Keywords: Upland cotton (Gossypiumhirsutum L.); Yield, early maturing; Salinity; Meta-analysis

\section{Introduction}

(C) Ankara Üniversitesi Ziraat Fakültesi

Upland cotton (Gossypiumhirsutum L.) plays an important role in supplying food (oil and protein), human 
fiber and livestock feed, and the need for cotton fabrics is constantly increasing in the world. It is the most important natural fiber of the world as a product of agriculture, industry and commerce, and now it accounts for $55 \%$ of the total natural fiber production of the world. Cotton seed oil is one of the best-quality vegetable oils. Cotton seeds are the second largest oilseed in the world after soybeans (Ahmadi \& Aghaalikhani 2012).

Cotton seed meal has 33 to 43 percent protein and is used as a protein supplement in the ration of the animal. In the cottony regions of Iran, Golestan province has a long history of cultivating this plant and due to its climatic conditions, the province has long been specialized in the production of cotton. For this reason, once known as the cotton capital and white golden land. Cotton produced in this province is considered one of the best-quality cotton with medium-long fibers in the world due to high effective fiber length, microny or Suitable elegance, high strength, elasticity and uniformity (Ahmadi \& Aghaalikhani 2012).

Numerous studies in the past have been carried out on various fields of agricultural sciences. For example, a lot of articles and research can be found on the effects of planting dates, density, environmental stresses, various fertilizers and other items. Although each research has a special value separately, but it is necessary to examine the results of this research in conjunction with each other to arrive at a conclusion about the factors affecting the yield of crops. For example, the effect of seed size on germination percentage has different results, some suggesting that smaller size seeds have a higher germination or emergence percentage (Stamp 1990). Some studies have found that the larger size seeds have a higher percentage (Baloch et al 2001; Cordazzo 2002). Cordazzo also, in some reports, it has been shown that seed size does not affect the percentage of germination (Bretagnolle et al 1995; Guillemin \& Chauvel 2011). If a researcher wants to review all these studies, it will be difficult to come up with a conclusion that larger seeds are better or smaller. Because the contradictory results are obtained, and each has sufficient scientific credibility. On the other hand, it is rarely possible for two identical studies to reach the same results. If the result of this compilation is the result of a statistical analysis of a large number of different papers and researches, statistically, it can be said that what the results was obtained in this series of studies. In this way, statistical analysis is called meta-analysis. The term meta-analysis was first used by Glass (1976) at the American Educational Research Association. The meta-analysis objective is to obtain more information from existing information that is achieved by overlapping the results of smaller studies and with one or more statistical analyzes. Thus, results that may not be discovered in smaller studies can be obtained by using meta-analysis of dozens of small studies. The need to summarize various researches has already been taken into consideration. To this end, some researchers are reviewing articles in which specific case studies have been carried out and are trying to summarize the effect. However, in most of them, there is no statistical method for reviewing and summarizing the results of research (for example, Matthews et al 2012; Taylor \& Salanenka 2012). Recently, a handful of researchers in agronomic science have used a meta-analysis method to compare the results of various researches (Wang et al 2013). However, searching on various internal sites such as sid, Magiran and Google showed that no research papers in agricultural fields have been used by this statistical method in Iran, and this method has been used only in the sciences and social sciences. The purpose of this study was to introduce a meta-analysis method for reviewing various agronomic studies and increasing appetite and knowledge in agronomic sciences.

Due to the lack of water resources in the country, identifying appropriate management and agronomic approaches is essential for the use of lower quality water (salty and brackish). Many areas of the country that are dedicated to cotton cultivation face the problem of soil water and soil salinity in these areas, saltresistant products such as cotton are cultivated. Hanson et al (2006) examined the drip irrigation system with salt water on cotton. With the application of 314 to $473 \mathrm{~mm}$ of water during the growth period, seed yield was changed from 3.51 to $3.63 \mathrm{t} \mathrm{ha}^{-1}$ and its yield was 1.11 to $1.19 \mathrm{t} \mathrm{ha}^{-1}$. Simsek et al (2004) Due to the problems caused by the use of salt water and consequently land saltiness, it is necessary to use drip irrigation for cotton cultivation in the near future. Yazar et al (2002) reported that using traditional irrigation systems for cotton cultivation caused irrigation water losses, reduced water use efficiency, and increased salinity and drainage problems. He also believes that salt and water stress during the growing season will reduce the production of the boll and the fall of the bolls, which reduces yields. Yazar et al (2002) results showed that cotton is more sensitive to salinity in early stages of growth and flowering compared to the rest of the growth stages. The height of the plant was affected by salinity and the dry weight of the seeds was

Tarım Bilimleri Dergisi - Journal of Agricultural Sciences 26 (2020) 94-103 
reduced by application of saline water, so that the dry weight of the seeds in soil salinities 7.7 and $12.5 \mathrm{dS}$ $\mathrm{m}^{-1}$, compared with $2 \mathrm{dS} \mathrm{m}^{-1}$ decreased by $52 \%$ and $84 \%$, respectively. Therefore, the purpose of this research is meta-analysis of the effects of salinity stress on growth and yield of cotton in Iran.

\section{Material and Methods}

In this study, the effects of salinity stress on early maturing, yield, and number of bolls and height of cotton in Iran were evaluated and articles related to the subject of the research were collected. After collecting data, it is typically determined in the scale of the effect size (Gurevitch \& Hedges 1999), and for the purpose of comparison, the confidence intervals are determined around the averages or slopes. The full description of the method of statistical computations of the meta-analysis has been presented by Gurevitch \& Hedges (1999). Further steps are briefly described. The first step in the implementation of the meta-analysis is calculated of the standard difference between the mean of the control treatment and the experimental treatments, which is called the effect of 1 (d). Thus, for each of the 46 independent experiments investigated in this meta-analysis, a value of $d$ is computed (Equation 1). It should be noted that the effect size was calculated separately for both fertilizer levels and for each fertilizer level.

$d=\frac{\bar{X}_{t}-\bar{X}_{c}}{S_{P}} \times J$

In which, respectively, the mean of control and fertilizer treatments, the $S_{p}$ is standard deviation of the combined mean and $\mathbf{J}$ correctional points for the bias of the standard deviations of the mean values. The values of $\mathrm{J}$ and $\mathrm{S}_{\mathrm{p}}$ are calculated from equations 2 and 3 respectively:

$$
\begin{aligned}
& J=1-\left[\frac{3}{4\left(d f_{c}+d f_{t}\right)-1}\right] \\
& S_{p}=\sqrt{\frac{d f_{c}\left(S_{c}^{2}\right)+d f_{t}\left(S_{t}^{2}\right)}{d f_{c}+d f_{t}}}
\end{aligned}
$$

In which $\mathrm{S}_{\mathrm{c}}$ and $\mathrm{S}_{\mathrm{t}}$ respectively, the standard deviation of the mean of control and fertilizer treatment, $\mathrm{df}_{\mathrm{c}}$ and $\mathrm{df}_{\mathrm{t}}$ respectively, are the degree of freedom of control and fertilizer treatment. If the values of the standard deviations of the meanings are not mentioned in the article, we can estimate the value of Sp based on the error of the test (MSE) variance in the articles presented in Equation 4:

$$
S_{p}=\sqrt{\left(\frac{n_{c}+n_{t}-2}{n_{c}+n_{t}}\right) M S E}
$$

Where; $\mathrm{n}_{\mathrm{c}}$ and $\mathrm{n}_{\mathrm{t}}$ are the number of replicas of control and treatment respectively.

Undoubtedly, all the tests under investigation do not have the same precision. Therefore, it is necessary to calculate for each experiment proportional to its accuracy, and then the amount of the effect of each experiment can be adjusted to it. To do this, first, the variance of the effect size for each experiment $\left(V_{d}\right)$ is calculated (Equation 5):

$V_{d}=\left[\frac{n_{c}+n_{t}}{n_{c} \times n_{t}}\right]+\left[\frac{d^{2}}{2 n\left(n_{c}+n_{t}\right)}\right]$ 
The contrary of this variance is weight of that test, so any test with a smaller variance will have more weight: Finally, a total or aggregate effect $\left(\mathrm{d}^{*}\right)$ is calculated, which in fact is the standardized difference between control and fertilizer treatments for all under consideration experiments (Equation 6):

$d^{*}=\frac{\sum w_{i} d_{i}}{\sum w_{i}}$

And its standard deviation $\left(\mathrm{S}_{\mathrm{d}^{*}}\right)$ will also be obtained from Equation 7:

$$
S_{d^{*}}=\sqrt{\frac{1}{\sum w_{i}}}
$$

The last step of the meta-analysis is the significance test $\mathrm{d}^{*}$, with the definiteness of $\mathrm{S}_{\mathrm{d}}{ }^{*}$, we can calculate the confidence interval $\mathrm{d}^{*}$. If this confidence interval is overlapping with zero, the size of the cumulative cohesive effect $\left(\mathrm{d}^{*}\right)$ is meaningless and the control Treatment is different from other treatments, otherwise the difference in treatment from control is significantly greater than zero. All calculations and graphs were done in Excel.

\section{Results and Discussion}

\subsection{Summary of the results of the experiments under investigation on salinity stress}

The results of this study showed that from 1996 to 2017, 15 papers and theses were published on the effects of salinity stress on yield, earliness and number of bolls in cotton. Of these, 15 papers have been the subject

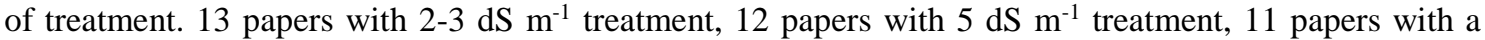
treatment of 6-7 $\mathrm{dS} \mathrm{m}^{-1}$, and 11 papers with a treatment of 8-9 $\mathrm{dS} \mathrm{m}^{-1}$ (Figure 1). With increasing Intensity of salinity stress, the yield (Figure 2) and number of bolls (Figure 4) decreased. Seed yield was $3008 \mathrm{~kg} \mathrm{ha}^{-}$ ${ }^{1}$ in control treatment, which was statistically significant with salinity stress of 8-9 dS m${ }^{-1}$. Early maturing in control treatment was obtained 70.8 days after planting. This difference was statistically significant with salinity stress treatment of $8-9 \mathrm{dS} \mathrm{m}^{-1}$ (Figure 3). The number of bolls in the control treatment was 21.41, which was statistically significant with salinity stress of $8-9 \mathrm{dS} \mathrm{m}^{-1}$. The results showed that in all cases, the effect of treatments with stress was less than control. The lowest yield was obtained in treatment of 8$9 \mathrm{dS} \mathrm{m}^{-1}$. The shortest processing time was obtained in treatment of 8-9 $\mathrm{dS} \mathrm{m}^{-1}$. The results showed that in all cases, number of bolls per plant was lower in stress plants than control. The lowest number of bolls per plant was obtained at 8-9 $\mathrm{dS} \mathrm{m}^{-1}$ treatment.

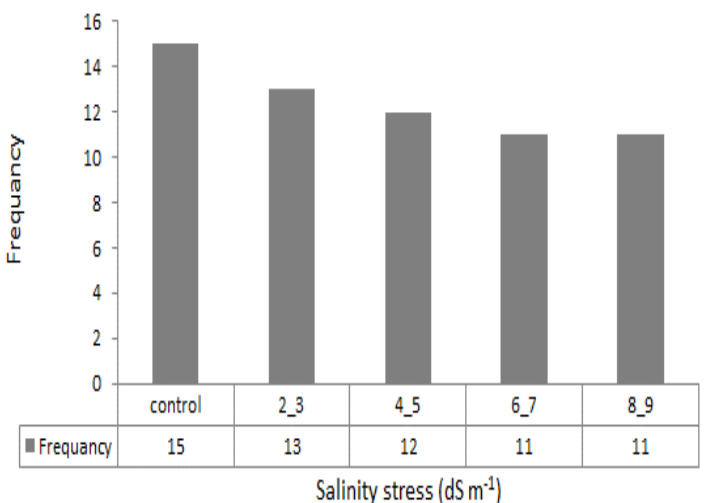

Figure 1- Frequently distribution of treatments in terms of salinity stress

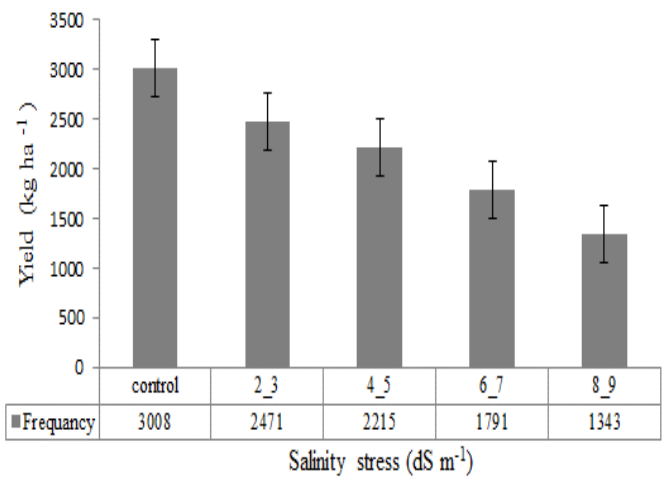

Figure 2- Seed yields of treatments in terms of salinity stress 


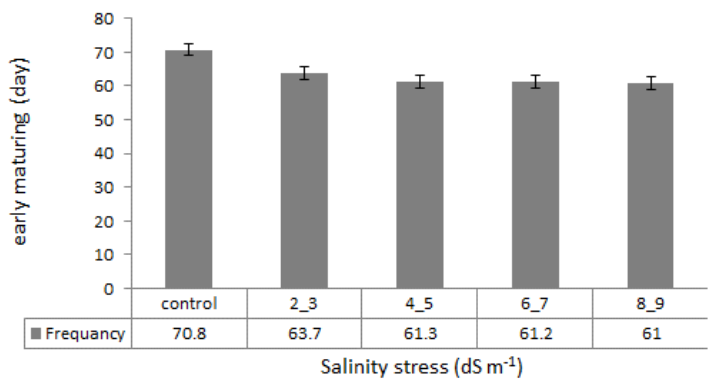

Figure 3- Early maturing in terms of salinity stress stress

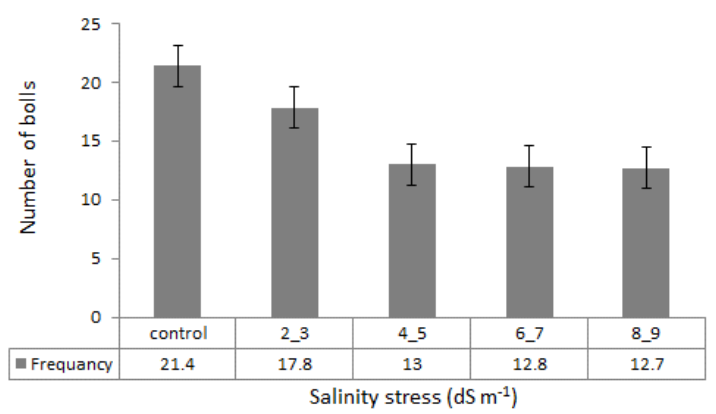

Figure 4- Number of bolls in terms of salinity

\subsection{Statistical comparison between salinity stress levels}

Effect size values for each of the four traits under study were normal distribution, and the normal distribution of this distribution is a prerequisite for continued meta-analysis. Gurevitch \& Hedges (1999) stated that if the distribution of the magnitude of the effect size is not normal, then the logarithm of the difference between the mean of the control and the experimental treatments for the implementation of metaanalysis should be used. The size of the effect can indicate the extent of the dispersion and the difference between the data in different experiments. The magnitude of the effect shown in the plot of the effect size and accumulation graph is measured by the $t$ test and, if it is meaningful, indicates that the difference between the different experiments was significant for a specific trait such as yield under a particular treatment, such as drought stress. On the other hand, if the standard deviation, which is shown in the plot of the effect size and accumulation graph and funnel graph, be higher, the probability of a significant trait such as yield under a treatment, such as drought stress, is reduced. In this study, in the plot of the effect size and accumulation, the size of the effect of the point and the standard deviation are shown respectively by the vertical and horizontal lines connected to the point respectively (half the standard deviation above the point and half the sub-point). Thevertical axis numbers in the accumulation graph represent the magnitude of the effect, as well as the difference between the vertical axis numbers representing the standard deviation. The standardized values for salinity stress effect on cotton yield were significant in all five treatments compared to control $(\mathrm{P}<0.001)$. It should be noted that the effect size for each trait is the difference between mean salinity of the mean of control treatment (without stress), so the positive values indicate that the average treatment with salinity stress is higher than the control treatment (Figure 5).

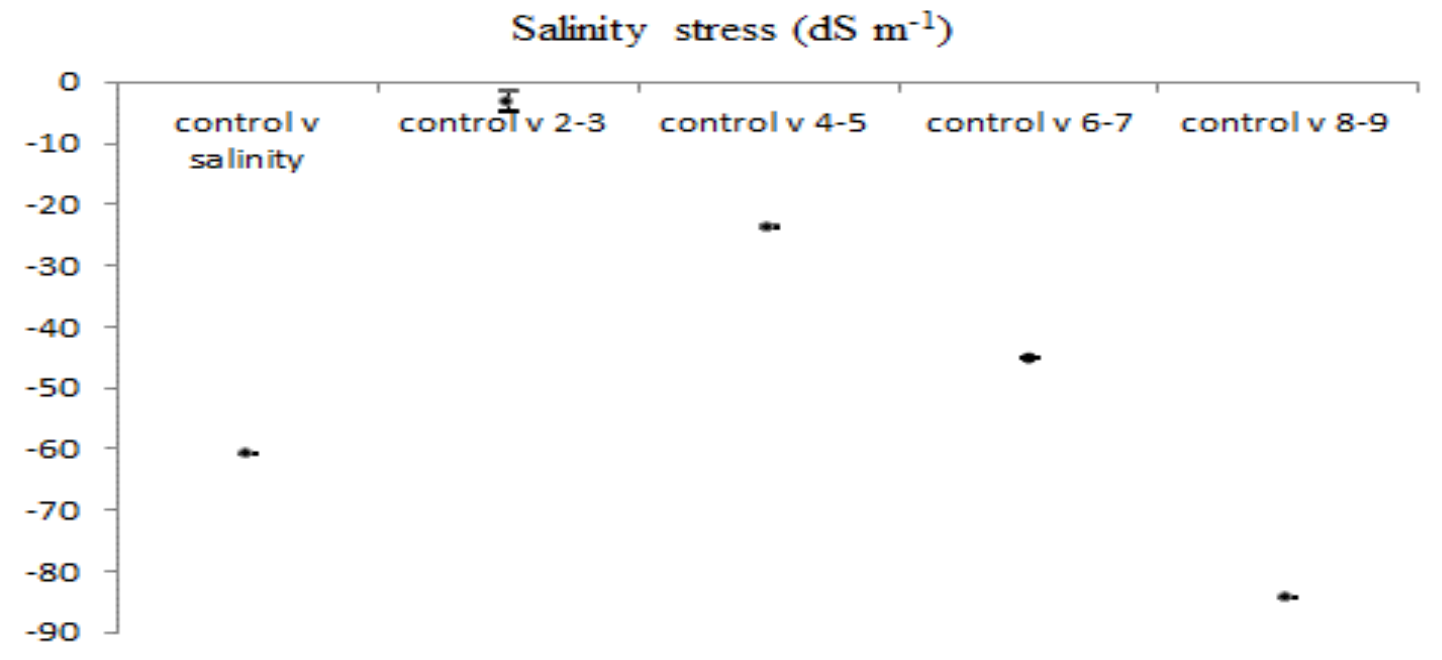

Figure 5- Comparison of the effects of different levels of salinity stress on performance. Vertical lines the confidence interval is the size of the combined effect of the stress test on the test. The first comparison is the control against the average of treatments with salinity stress 
The standardized values for the effect of salt stress on early maturing of cotton were significant in all five treatments compared to control. The results showed that in all cases, early maturing tension treatments were less than control (Figure 6).

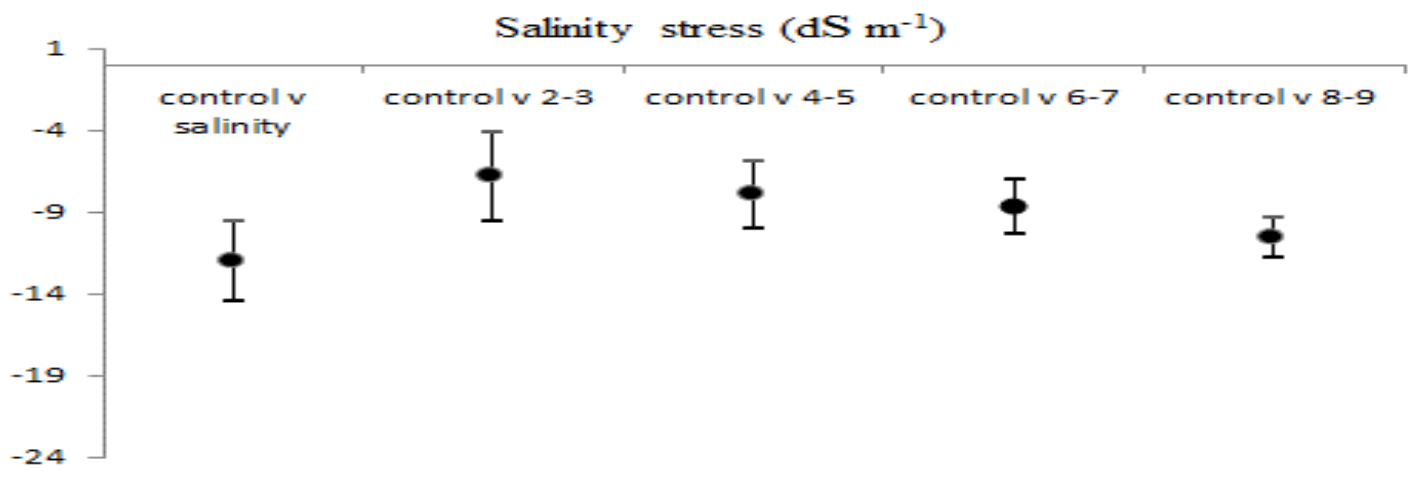

Figure 6- Comparison of the effects of different levels of salinity stress on prematurely. Vertical lines of the confidence interval of the size of the tuned combined effect among the trials is under investigation. The first comparison is the control against the average of treatments with salinity stress

The standardized values for the effect of salinity stress on number of bolls per cotton plant were significant in comparison to total salinity treatments, 2-3 $\mathrm{dS} \mathrm{m}^{-1}, 6-7 \mathrm{dS} \mathrm{m}^{-1}$ and 8-9 $\mathrm{dS} \mathrm{m}^{-1}$ with control $(\mathrm{P}<0.001)$ (Figure 7).

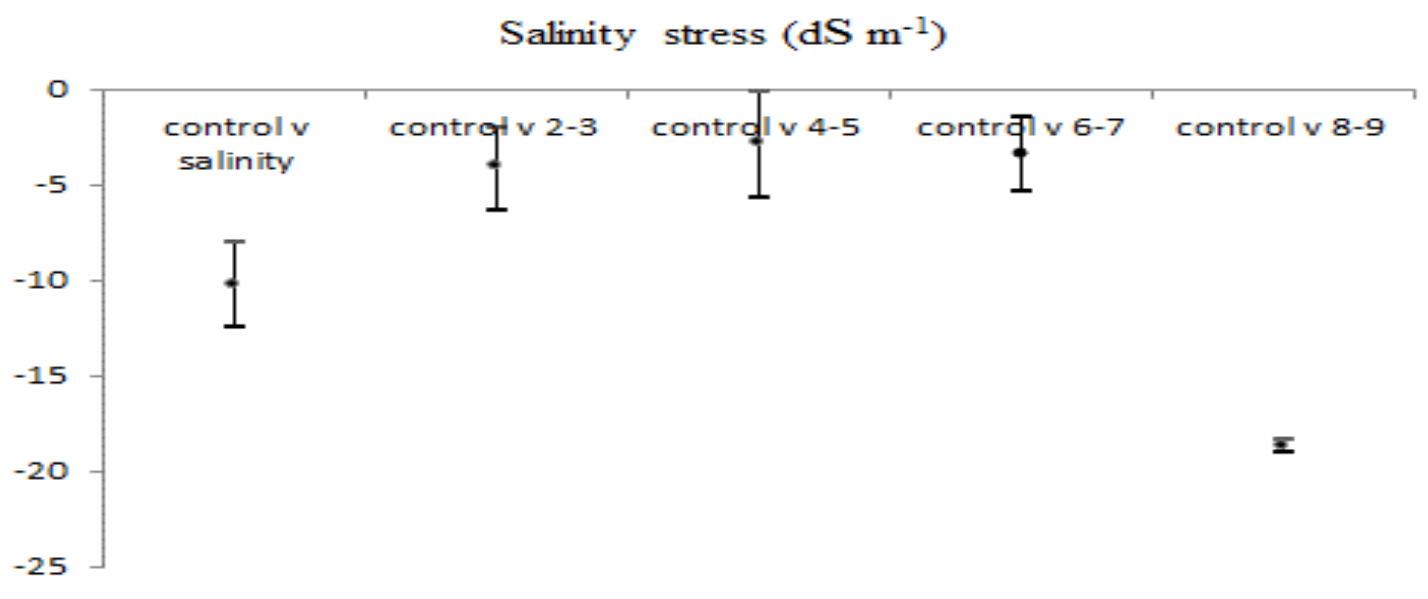

Figure 7- Comparison of the effects of different levels of salinity stress on number of bolls per plant. Vertical lines of the confidence interval of the size of the tuned combined effect among the trials is under investigation. The first comparison is the control against the average of treatments with salinity stress

\subsection{Accumulation graph and funnel graph}

Studies data are located on the vertical axis of the accumulation graph. In some cases, studies are sorted according to the year of publication, and in some cases, based on sample size. In any case, a better sorting criterion is the criterion for most uniformity. Studies are divided into two groups of meaningful and nonsignificant, which, if the treatments cut off the zero line, are not significant. If the treatments do not interrupt the zero line, this study is significant. Also, if meaningful research is done, the right side of the axis is zero, that is, drought stress will increase the desired trait if left side of it indicates that the trait was reduced to drought stress. 
From the collected and reviewed research collections, Figure 8, has been obtained and its accumulation graph is related to the impact of cotton yield on the salinity stress as outlined below. Regarding the diagrams, among studies in which salinity stress reduced yield, one can refer to the study by Nikzadfar et al (2012) and Anagholi et al (2016). Among these papers, Nikzadfar et al (2012) have the highest weight and the lowest confidence intervals. As it is seen, the research used in this trait shows the effect of treatments very close to zero and with a low confidence interval. One of the high-weight researches is the paper by Nikzadfar et al (2012), Afrasiab et al (2015).

In the funnel graph, Figure 9 shows that the articles are in the 95\% range and have a lower and more inferior bias, which is considered to be a positive result of the research. As shown in Figure 9, only 1 study with negative effect on the effect of salinity stress on the performance was not significant and was located outside the funnel.

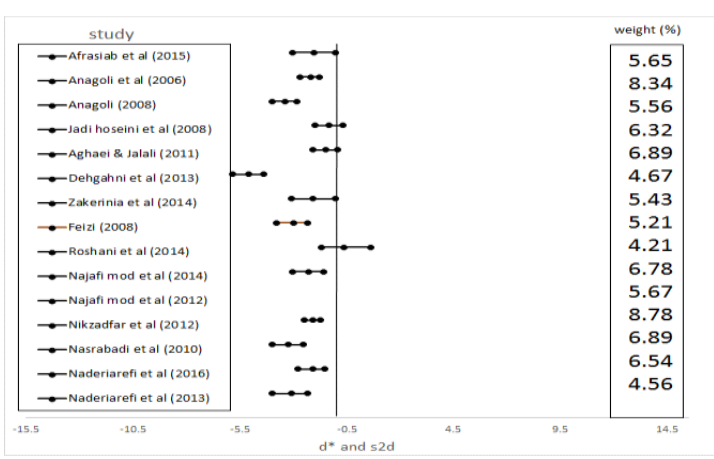

Figure 8- Accumulation graph, effect of yield on salinity stress

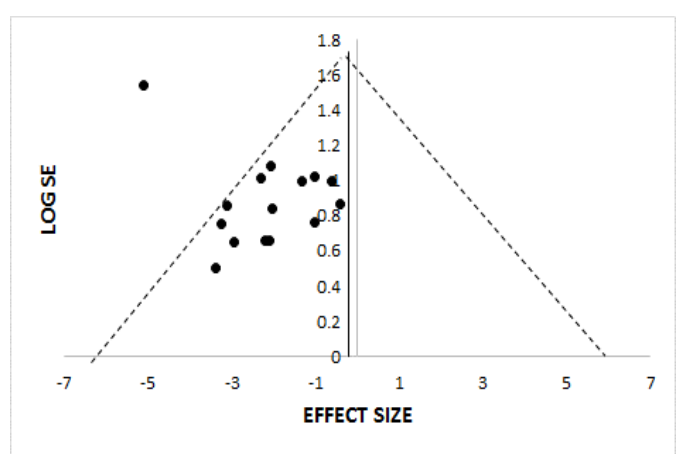

Figure 9- Funnel graph, effect of yield on salinity stress

From the collected and reviewed research collections, Figure 10, has been obtained and its accumulation graph relates to the study of the effect of cotton aging on the salinity stress described below. Regarding the charts, among which studies have shown that salinity stress aging can be reduced, one can refer to the study by Nikzadfar et al (2012) and Anagohli et al (2016). Between these articles, the article of Naderiarefi et al (2016), has the highest weight and the lowest confidence interval. As you can see, the research used in this trait shows the effect of treatments near zero. Among the high-weight researches, Najafi Mod \& Colleagues (2014) are mentioned. On the funnel graph, graph 11, shows that the articles are in the 95\% range, with a lower and more inefficient amount of paper, which is considered to be a positive result of the research. As it is estimated from Figure11, only 2 positive-for-effect paper have no significant effect on the effect of salinity stress on outbreak.

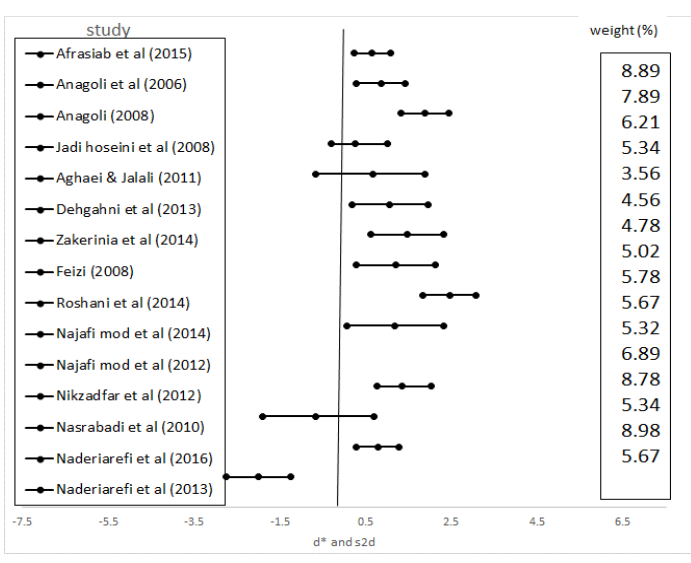

Figure 10- Accumulation graph, early maturing impact on salinity stress

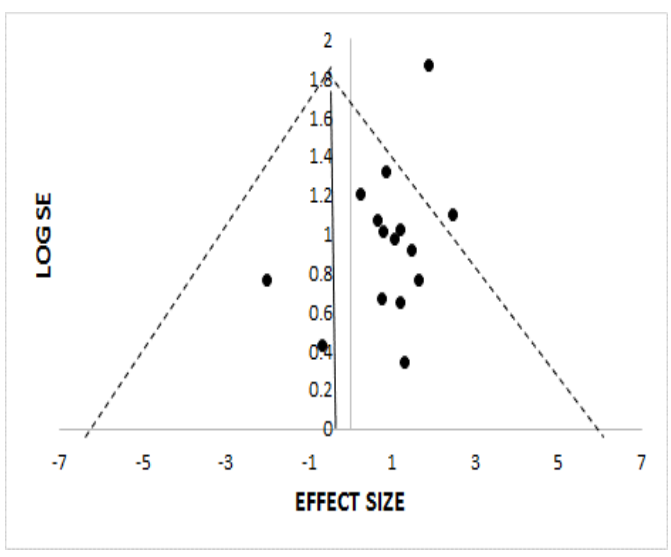

Figure 11- Funnel graph, early maturing impact on salinity stress 
From the collected and reviewed research collections, Figure 12, has been obtained and its accumulation chart is related to the study of the impact of the number of cotton balls against the salinity stress that is plotted below. According to the diagrams, from studies in which salinity stress reduces the number of bolls, can be noted the study of Anagholi et al (2016). Among these articles, Afrasiab et al (2015) have the highest weight and minimum confidence intervals. As can be seen, the research used in this trait shows the effect of treatments near zero and with a low confidence interval. One of the high-weight researches is the Feizi's research (2008).

In the case of the funnel, Figure 13 shows that the papers are in the range of $95 \%$, the bias is less and its unbiased is more, which is considered to be a positive result of the research. As shown in Figure13, one negative and one positive study on the effect of salinity stress have not significant effect on number of bolls and have been out of the funnel.

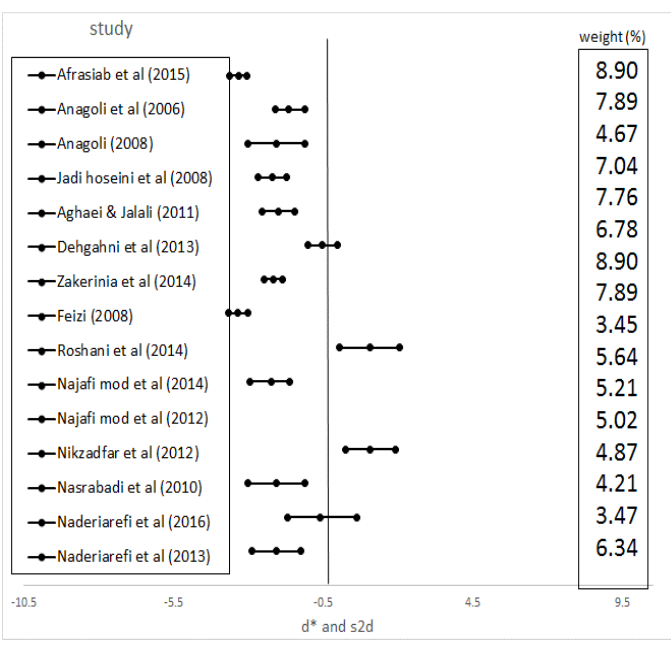

Figure 12- Accumulation graph, number of bolls affected by salinity stress

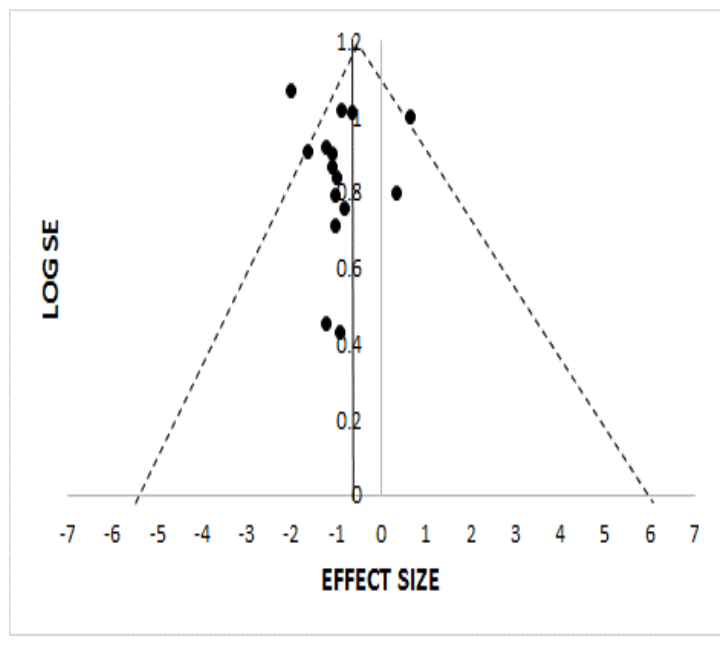

Figure 13- Funnel graph, number of bolls affected by salinity stress

Since plant growth has a close relationship with soil salinity of the root development zone, so, under irrigation water salinity conditions, the plant generates more energy to absorb water and food. In this condition, the plant components are affected by soil water salinity and due to salt tolerance, they have a severe decrease compared to conventional conditions. The set of these factors will reduce the height, reduce the number of bolls per plant, and ultimately reduce plant yield. On the other hand, salt stress can lead to premature production and, consequently, reduced yield (Afrasiab et al 2015). In case of increasing salinity of water relative to optimal conditions, reduction of yield components such as number of bolls per plant is significant, which, in turn, affects performance.

Product performance is affected by the amount of water salinity. So that whatever the salinity decreases, the yield loss is also reduced. The results from other studies show that By increasing salinity of irrigation water and causing osmotic pressure, plant root strength decreases to absorb the water in the root environment, therefore, the accumulation of solutes in the root zone causes less water and nutrient absorption by the plant (as compared to the proper irrigation water for salinity) In this situation, the yield of the plant is reduced Yang et al (2011).

\section{Conclusions}

In general, the results of this study showed that salinity stress can reduce yield of cotton by reducing the number of bolls and also can cause early maturing on cotton. The lowest and highest yield and number of bolls in cotton were observed respectively in 8-9 $\mathrm{dS} \mathrm{m}^{-1}$ treatment and control. Also the shortest processing time was obtained in treatment of 8-9 dS m${ }^{-1}$. The result of meta-analysis indicated that salinity effects were 
significant in reducing yield number of bolls and increasing early maturing in cotton. Regarding the diagrams, among studies in which salinity stress reduced yield, one can refer study by Nikzadfar et al (2012). Among these papers, Nikzadfar et al (2012) have the highest weight and the lowest confidence intervals. As it is seen, the research used in trait shows the effect of treatment very close to zero and with a low confidence interval. One the high-weight researches are the paper by Nikzadfar et al (2012), Afrasiab et al (2015). Regarding the charts, among which studies have shown that salinity stress can be reduced aging, one can refer to the Nikzadfar et al (2012) and Naderifar et al (2016), has the highest weight and lowest confidence interval. As you can see, the research used in this trait shows the effect of treatments near zero. Among the high-weight researches, Najafi \& Colleagues (2014) are mentioned. According to the diagrams, from studies in which salinity stress reduces the number of bolls, can be noted the study of Anagholi et al (2016). Among these articles, Afrasiab et al (2015) have the highest weight and minimum confidence intervals. As can be seen, the research used in this trait shows the effect of treatments near zero and with a low confidence interval. One of the high-weight researches is the Feizi's research (2008). At end it is necessary to apply special programs to reduce the effect of salinity stress on cotton plant. On the other hand, given the growing trend of soil salinity in Iran, the sensitivity of this is more and more understandable.

\section{References}

Afrasiab P, Delbari M, Asadi R \& Mohammadi E (2015). Effect of soil section and water salinity on yield and components yield of cotton. Journal of Plant Production Research 22(3): 295-311

Ahmadi M \& Aghaalikhani M (2012). An analysis of energy consumption of cotton cultivation in Golestan province to offering strategy for increasing resources productivity. Journal of Agro Ecology 4(2): 151-158

Anagholi A, Rousta M J \& Azari A (2016). Selection of salt tolerance varitieis of cotton by using of tolerant indices. Arid Bio Scientific and Research Journal 2: 1-9

Baloch H A, DiTommaso A \& Watson A K (2001). Intrapopulation variation in Abutilon theophrasti seed mass and its relationship to seed germinability. Seed Science Research 11: 335-343

Bretagnolle F, Thompson J D \& Lumaret R (1995). The influence of seed size variation on seed germination and seedling vigor in diploid and tetraploid DactylisglomerataL. Annals of Botany 76: 605-615

Cordazzo C V (2002). Effect of seed mass on germination and growth in three dominant species in southern Brazilian coastal dunes. Brazil. Journal of Biology 62: 427-435

Feizi S (2008). Watering irrigation management on soil salinity in a period of rotation. Water Management and Irrigation Journal 5(1): 11-25

Glass G V (1976). Primary, secondary and meta_analysis. Educational Research, 5. pp. 23-34

Guillemin J P \& Chauvel B (2011). Effects of the seed weight and burial depth on the seed behavior of common ragweed (Ambrosia artemisiifolia). Weed Biology and Management 11: 217-223

Gurevitch J \& Hedges L V (1999). Statistical issues in ecological meta-analysis. Ecology 80: 1142-1149

Hanson B R, Hutmacher R B \& May D (2006). Drip irrigation of tomato and cotton under shallow saline ground water conditions. Irrigation and Drainage Systems 20: 155-177

Matthews S, Noli E, Demir I, Khajeh Hosseini M \& Wagner M H (2012). Evaluation of seed quality: from physiology to international standardization. Seed Science Research 22: S69-S73

Naderiarefi A, Ahmadi A, Tavakoli A R, Vafaietabar M A R \& Sabikdast M (2016). The effect of issue stress on physiological characteristics of leaf and drought resistance of different cotton genotypes. To Agricultural Crop Journal 18(4): 987-999

Najafi Mod M H, Alizadeh A, Davari K, Kafi M \& Shahidi A (2014). Study on the yield assesse indexes and determinate optimum depth irrigation for two cultivars of cotton on different level of water salinity. Journal of Water and Soil 26(4): 990-998 
Nikzadfar M, Fathi D \& Sohrabi B (2011). The effect of various level of water and nitrogen fertilizers on quality and quality of cotton. First National Conference on Meterology and Water Management, Tehran University, Fall; 2021 Desember

Simsek M, Kakira M \& Tonkaz T (2004). The effects of different drip irrigation regimes on water melonyield and yield components under semi-arid climatic conditions. Journal of Agriculture Research 55: 1149-1157

Stamp N E (1990). Production and effect of seed size in a grassland annual (Erodiumbrachycarpum, Geraniaceae). American Journal of Botany 77: 874-882

Taylor A G \& Salanenka Y A (2012). Seed treatments: phytotoxicity amelioration and tracer uptake. Seed Science Research 22: S86-S90

Wang M, Wang Q \& Zhang B (2013). Response of miRNA and their targets tosalt and drought stresses in cotton (Gossypiumhirsutum L.). National Library of Medicine 530(1): 26-32

Yang G, Tang H, Nie Y \& Zhang H (2011). Response of cotton growth, yield and biomass to nitrogen split application. European Journal of Agronomy. pp. 34-45

Yazar A, Sezen S N \& Severen S (2002). LEPA and trickle irrigation of cotton in the Southeastern Anatolian project (GAP) area in Turkey. Agriculture Water Management 54: 89-203 